\title{
A COMMUNITY DEVELOPMENT CRITIQUE OF COMPULSORY INCOME MANAGEMENT IN AUSTRALIA
}

\author{
Una crítica del desarrollo comunitario sobre la gestión obligatoria de \\ ingresos en Australia
}

Philip Mendes ${ }^{1}$, Jacinta Waugh And Catherine Flynn

(Social Inclusion and Social Policy Research Unit, Department of Social Work, Monash University)

The larger project on which this paper is based was funded by Family Care

Shepparton and Berry St Victoria

\begin{abstract}
The introduction of compulsory income management - sometimes called welfare quarantining - for sub-groups of income security recipients within Australia has provoked considerable contention. This paper examines the specific introduction of the Place-Based trial in the rural Victorian region of Greater Shepparton from July 2012. Utilizing key community development principles, we critically analyse processes of implementation and evaluation, and argue that placebased income management has involved a centralized top-down process. In contrast, we recommend a bottom-up approach which would allow the local community to play a key role in defining the problem, and identifying policy solutions.
\end{abstract}

Key words: income management, evaluations, income security, community development, Australia

\section{Resumen}

La introducción de la gestión de ingresos obligatorios -a veces llamada imposición de «cuarentena» a las prestaciones de la asistencia social- para subgrupos de beneficiarios dentro de Australia ha suscitado considerable controversia. Este artículo examina la introducción de una prueba basada en la región rural de Victoria de Gran Shepparton desde julio de 2012. La utilización de los principios fundamentales del desarrollo de la comunidad y el análisis crítico de los procesos de implementación y evaluación, demuestra que la gestión de los ingresos basado en el lugar ha implicado un proceso centralizada de arriba hacia abajo. Por el contrario, se recomienda un enfoque de abajo hacia arriba que permita a la comunidad local a jugar un papel clave en la definición del problema y la identificación del las políticas para crear soluciones.

Palabras clave: Australia, desarrollo de la comunidad, gestión de ingresos, evaluación, seguridad de ingresos.

Recibido: 05/09/2013

Aceptado: 14/10/2013

Publicado: 05/11/2013

1. Department of Social Work, Monash University, PO Box 197, East Caulfield, Victoria, Australia, 3145 - Philip.Mendes@monash.edu 


\section{Introduction}

The introduction of income management - sometimes called welfare quarantining - for sub-groups of Australian income security recipients within the Northern Territory and subsequently a number of other trial sites has provoked considerable contention. Much of this debate has concerned different philosophical approaches, particularly individual versus structural, to addressing chronic disadvantage. There has also been intense discord over the effectiveness of income management programs in achieving their stated aims. In this review, we utilize key community development principles such as social inclusion, empowerment and participation to critically analyse processes of implementation and evaluation. We argue that place-based income management has involved a centralized top-down process. In contrast, we recommend a bottom-up approach which would allow the local community to play a key role in defining the problem, and identifying policy solutions.

Income management (IM) is the quarantining of a set percentage of income security payments (government welfare benefits) - usually somewhere between 50 and 70 per cent - into a special account for the exclusive purchase of pre-determined essential household items such as food, rent, clothing, health care, education and training, child care, public transport and energy bills. The remaining proportion of the payment is paid directly to the recipient to use at their discretion. Income managed funds cannot be used for prohibited items such as drugs, alcohol, cigarettes, gambling and pornography (Buckmaster and Ey, 2012). Income management is not completely new to Australia. There are other existing welfare quarantining schemes such as the Centrepay deduction scheme introduced by the Department of $\mathrm{Hu}$ man Services, and the Food Card schemes established by non-government organisations in the Northern Territory (Buduls, 2013). But those schemes are completely voluntary, whereas most of the new schemes discussed below are compulsory.

There are currently six different versions of Income Management in Australia. They consist of:

1. The Child Protection measure (CPIM) whereby welfare recipients in the Northern Territory and parts of Western Australia are referred by a child protection officer to the Department of Human Services (DHS) to have their income managed. This measure is applied to parents who abuse or neglect their children, or who fail to ensure their school attendance 
2. The Vulnerable Welfare Payment Recipients measure (VWPR) whereby welfare recipients in the Northern Territory are referred for income management by a DHS social worker as a result of poor financial management, family violence, mental health concerns or other factors.

3. The Voluntary Income Management Measure (VIM) whereby people living in the Northern Territory have chosen to be involved in income management arrangements.

4. The School Enrolment and School Attendance Measure (SEAM) applied to parents who fail to ensure their child is enrolled in or regularly attending school.

5. The Queensland Commission (Welfare Reform) measure involving welfare recipients in Cape York whom a statutory body called the Family Responsibilities Commission has ordered should be subject to income management for engaging in dysfunctional behaviour.

6. Place-Based Income Management (PBIM) involving welfare recipients living in one of five targeted communities across Australia who have been referred for Child Protection Income Management (CPIM) or the Vulnerable Welfare Payment Recipients (VWPR) measure, or who choose to participate in Voluntary Income Management (Buckmaster and Ey, 2012; Buckmaster, Ey and Clapdor, 2012).

This article is part of a larger analysis of the government evaluations of income management programs in Australia (Authors, 2013). That analysis examined the key methodologies and limitations of the current frameworks used to evaluate income management in the Northern Territory and other jurisdictions. All seven independent assessments (i.e. those evaluations undertaken independently of government-imposed criteria) of IM published since its introduction (2007 - 2013) were identified. The authors engaged in a content analysis of these papers, to identify key themes, both methodological and in the findings presented in these studies. Such an approach is described by Bryman (2012) to be a useful and appropriate analytic tool to uncover trends and patterns in qualitative data. Given the lack of existing research, a flexible approach was taken with this analysis, with codes and ultimately themes generated from the data, rather than from predetermined categories.

Additionally, given the newness of this issue, we augmented this formal analysis of existing evaluations with informal discussions with two key nongovernment welfare service providers, Family Care and Berry Street Victoria, based in the PBIM site of Shepparton. These stakeholders strongly argued that any effective evaluation needed to consider whether or not local community 
representatives had been substantially consulted in the development and implementation of income management policy (Authors, 2013). That stakeholder critique of the absence of a community development approach has been applied in this article both to the implementation and evaluation of PBIM in Shepparton.

That analysis identified five fundamental themes that were arguably not sufficiently covered in the official evaluations, and formed the basis of an alternative evaluation framework. These themes included choice and control, the quality of decision making, consultation with local community members, structural disadvantage, and economic cost, and are discussed more fully elsewhere (Authors, 2013).

\section{Background and Chronology}

The Coalition Government that headed Australia from 1996-2007 was strongly influenced by neo-liberal philosophy, and imposed an increasing conditionality on the income security system (Billings, 2010; Mendes, 2008). In June 2007, the Government announced the establishment of the Northern Territory Emergency Response (NTER). The NTER was introduced as a result of the Little Children Are Sacred report published by the Northern Territory Board of Inquiry into the Protection of Aboriginal Children from Sexual Abuse. The report found that child sexual abuse was serious, widespread and often unreported. It urged that Aboriginal child sexual abuse in the Northern Territory be designated as an issue of urgent national significance by both the Australian and Northern Territory Governments, and that both governments undertake genuine consultation with Aboriginal people in developing service responses (Wild and Anderson, 2007).

Consequently, the NTER included a range of measures arguably seeking to address such abuse by tackling alcohol abuse, improving school attendance and reforming public housing arrangements. Additionally, 50 per cent of all income support and family assistance payments for Indigenous residents of remote Northern Territory communities would be quarantined via Income Management (IM) to ensure payments were spent on food, school nutrition, rent and other essential items for the care of children and not on alcohol, cigarettes, pornography or gambling. These measures required a suspension of the Racial Discrimination Act so that they could be applied exclusively to Indigenous Australians living in 73 prescribed communities, associated outstations and 10 town camp regions of the Northern Territory. The NTER plan was applied without any consultation with all people living in these 
Indigenous communities regardless of their individual circumstances or capacity (Australian Council of Social Service (ACOSS), 2008).

The Australian Labor Party (ALP) Government elected in November 2007 chose to continue the NTER including IM, but invited an independent Review Board chaired by West Australian Indigenous leader Peter Yu to present a progress report on the intervention. The report of the review, which was released in October 2008, agreed that the intervention had made some positive changes in the Northern Territory in relation to improving housing, health and education. But it called for an end to the compulsory income management system except where child protection or school attendance matters were involved, and urged a reinstatement of the Racial Discrimination Act (Australian Government, 2008).

Despite some identified benefits, the report also exposed widespread discontent with the 'top-down' nature of the program. Instead, Indigenous Australians urged the government to consider an alternative 'bottom-up' approach based on a community development framework that would allow 'local communities to determine and prioritize their needs'. The report defined community development as an approach 'led by the community and partnered by the government'. It emphasized the importance of 'investment in local skills and capacities and leadership', and argued the need for 'a genuine engagement' with Aboriginal communities (Australian Government, 2008:8, 14). This proposal for a program based on community development principles and practice seems, however, to have been largely ignored by the government.

The government introduced a Basics Card in late 2008 which is a personal identification number protected card that enabled participants to use their income managed funds to purchase food and other essential items at authorized stores. The card was initially used only for Indigenous recipients, and has attracted controversy due to the restrictions it places on the consumer choice of IM recipients who are only able to shop at designated retailers. This is of concern given that other stores may be more conveniently located, and sell cheaper and/or better quality products than the large retailers. IM users have also complained of the government's DHS agency failing to make payments on time to utility companies, of difficulties in using the Basics Card to purchase prescription medicines, problems in checking the balance on their Card, and a general sense of shame associated with the use of the Card (ACOSS, 2010; Equality Rights Alliance, 2011; Goulbourn Valley Community Legal Centre Pilot, 2012).

In May 2009, the government released a discussion paper on the NTER which cited various positive impacts of IM in the Northern Territory. The 
paper rejected the recommendations of the earlier review report pertaining to IM, arguing on the basis of some submissions to the NTER Review Board that it had provided benefits for women and children such as increased household expenditure on food and other essential items, less gambling and drinking, and reduced alcohol-fuelled violence. They announced that IM would be extended for at least another 12 months, but they also stated that they would re-draft IM measures via parliamentary legislation to make them comply with the Racial Discrimination Act (Australian Government, 2009).

Further consultations were undertaken with Indigenous participants plus representatives of regional and major Indigenous stakeholder organisations in June and August 2009. But participants were only provided with a choice of two limited options: to continue the existing IM model, or to allow individuals to request exemptions on the basis of demonstrated responsible behaviour. Participants were not given the option of dismantling IM entirely, or transforming it into a voluntary scheme (Australian Government, 2009). The reluctance of the government to engage in genuine consultations to attain community views on whether or not to continue IM was to remain an ongoing concern (ACOSS, 2010; Nicholson, Behrendt, Vivian, Watson and Harris, 2009).

The Social Security and other Legislation Amendment (Welfare Reform and Reinstatement of Racial Discrimination Act) Bill 2009 was passed by Parliament in 2010. In contrast to the NTER income management which affected all residents of prescribed communities, the Bill introduced a new form of income management which applied only to five targeted groups of income security recipients: disengaged young people aged 15-24 years who have been on nominated payments for at least 13 of the past 26 weeks; long-term welfare recipients over 25 years who had received income security payments for more than 52 weeks in the last two years; income security recipients deemed vulnerable by a Centrelink social worker as a result of poor financial management, family violence, mental health concerns or other factors; those individuals referred by child protection authorities, and persons who voluntarily choose income management arrangements. Another action was the reinstatement of the Racial Discrimination Act via amendments to the original NTER measures, and the restoration of appeal and review rights for participants (CALC, 2010). From July 2012, a targeted model of IM called Place-Based Income Management (PBIM) was introduced for a five year trial in five new locations across Australia - one in Victoria (Shepparton), two in Queensland (Logan and Rockhampton), and one each in New South Wales (Bankstown) and South Australia (Playford). 
Concurrently, a welfare reform trial has been taking place in four Cape York communities in far north Queensland since July 2008, based on a partnership between the communities, the Australian Government, the Queensland Government and the Cape York Institute for Policy and Leadership, headed by Aboriginal campaigner Noel Pearson. The aim of the trial, which was recently extended till 2014, is to re-establish positive social norms and reduce passive welfare receipt in these communities. The programs differ from the federal IM in that they are voluntary, income management is only applied as a last resort, and the program planning involved substantial prior consultation with local community leaders (Billings, 2010; Pearson, 2011).

The aims of the range of income management programs vary from the specific to the highly general. The original aim of IM within the NTER was argued to be to protect children from abuse or neglect, and women from financial harassment or 'humbugging' and violence. An associated aim was to focus funds on essential household items such as food and clothing, and reduce or eliminate spending on substance use, gambling and pornography which was seen to be associated with child sexual abuse. IM has also been described as a budgeting tool to assist families, particularly those with alcohol abuse or mental health concerns, to manage their finances (Australian Government, 2013; Deloitte Access Economics, 2013).

But the government has also suggested some much broader objectives of IM involving behavioural change such as reducing welfare dependency, promoting self-reliance and responsibility, improving parenting skills, and increasing the capacity to learn work skills and potentially attain employment (Bray, Gray, Hand, Bradbury, Eastman and Katz, 2012; Macklin, 2010).

All these aims seem to target changes in the individual behaviour of recipients. But these personal deficits are arguably closely related to broader structural and systemic causes of disadvantage. For example, these would include the low level of income security payments and lack of affordable housing, which push many recipients into poverty and associated family breakdown. Additionally, there tends to be minimal education, training and employment opportunities available in many of the targeted communities. Some remote communities lack access to healthy and affordable food, and there is also the intergenerational trauma experienced by many Indigenous Australians due to experiences of racism, dispossession, institutionalization and the removal of children (ACOSS, 2010; Billings, 2010; Cox, 2010; Western Australian Council of Social Service (WACOSS), 2011). However, the income management programs do not appear to recognize or address the broader structural and communal context of individual disadvantage. 


\section{Why Place-Based Income Managememt?}

Place-based programs are intended to address the concentration of disadvantage in specific locations or postcodes. It has been argued that holistic programs which target groups of people with multiple forms of disadvantage in specific neighbourhoods will be more effective than universal programs in promoting opportunities for disadvantaged communities, and preventing inter-generational poverty (Byron, 2010; Green and Zappala, 2000).

The most significant Australian argument in favour of place-based programs was presented by social work academic Tony Vinson. Vinson argues in favour of positive interventions to provide opportunities for the social inclusion of disadvantaged people in local communities (2010). He uses a wide range of indicators to demonstrate spatial inequality and geographic disadvantage. These are:

- Social distress: low family income, rental distress, home purchase distress, lone person's households

- Health: low birth weight, childhood injuries, deficient immunisation, disability/sickness support, mortality (life expectancy), mental health patients treated in hospitals/the community, and suicide

- Community Safety: confirmed child maltreatment, criminal convictions, prison admissions, domestic violence

- Economic: unskilled workers, unemployment, long-term unemployment, dependency ratio, low mean taxable income, limited computer use/internet access

- Education: non-attendance at pre-school, incomplete education (1724 year olds), early school leaving of local population, post-schooling qualifications

- Community engagement: membership of local group, membership of groups that tackle local problems, local volunteering, help from neighbours when needed, feel safe after dark, trust people, attendance at local community events, feel valued by society (Vinson, 2007: 6).

Place-based programs claim to utilize community development principles in addressing social disadvantage. By community development, we refer to the employment of community structures to address social needs and empower groups of people. A community development approach to a social problem such as poverty or limited housing would involve engaging with community members who were poor or homeless, consulting with those community organizations that are involved with and have knowledge of the experiences of 
disadvantaged groups, and ensuring that the local community per se plays a key role in both defining the causes of the problem, and identifying potential policy solutions. Key principles would be the inclusion of all local residents including potentially marginalized groups in the policy development process, and the empowerment of disadvantaged groups by giving them the capacity alongside other community members and organisations to participate in the development and implementation of policy strategies (Kenny, 2011).

The Australian Government seems to have given serious consideration to the introduction of place-based policies aligned with community development. For example, a report by the government's Social Inclusion Board identified the principles underlying effective place based programs as including the enhancement of local capacity and resources, and the devolution of policy development to local groups with local expertise in order to define both problems and solutions. Overall, the Board recommended a decentralized community development approach to policy making (Australian Social Inclusion Board, 2011). An accompanying report noted that the main barrier to facilitating local community control was 'the reluctance of government agencies to give up power to others outside their field of activity' (Australian Social Inclusion Board, 2011: 25).

Australian and UK evaluations of community renewal programs that have applied at least some of these principles suggest a number of positive outcomes including greater resident participation, improvements in social and community cohesion, and better employment outcomes (Fawcett et al, 2010). Similarly, a number of evaluations of welfare services in Indigenous communities have shown that they are most effective when the local community is heavily involved in both the planning and implementation stages (Al-Yaman and Higgins, 2011). Other authors draw specific attention to community development interventions that have worked to enhance school attendance and retention rates for Indigenous children. These programs appear to be most effective when introduced as a result of ongoing consultations between schools and Indigenous parents and communities (Behrendt and McCausland, 2008).

But many place-based programs have not adhered to community development principles. For example, a study of 36 place-focused initiatives in Western Sydney found that projects often narrowly targeted the problems of disadvantaged groups rather than the community or structural context of social problems, and failed to introduce sustainable local outcomes (Randolph, 2004). Another study suggested that too often place-based programs are controlled by centralized government authorities, community consultations are limited, and local knowledge and expertise is marginalized (Morrison, 2008). 
A particular identified concern is that place-based programs can serve to further pathologize excluded groups by targeting changes in individual behaviour, rather than identifying broader community and structural policy reforms (Smyth, 2008). An example of this might be policies which simply aimed to reduce the number of drug users or street sex workers in a particular neighbourhood, rather than introducing strategies that improved outcomes for all community members including those involved in drug use or sex work. Similarly, place-based programs may potentially blame the deficits of the local community for social problems such as drug use or unemployment, rather than identifying broader structural factors which go beyond locality such as inadequate funding of rehabilitation facilities for substance users, or low levels of business and government investment in employment-generating industries.

This emphasis on blaming groups of disadvantaged people seems to be present in the stated aims of PBIM which are to help create financial stability for families by promoting improved budgeting, increase their economic participation, ensure that the priority needs of families including particularly the care, welfare and education of children are met, and address vulnerable circumstances such as homelessness (Australian Government, 2012a; 2012b). These objectives do not seem to be significantly different to those stated for other IM programs. Specifically, there is no mention of addressing the broader structural context of disadvantage. Equally, there is no reference to specific local social and economic factors that may have shaped the nature of disadvantage. Most importantly, it does not appear that any local community groups in Shepparton or the other four trial locations were given the opportunity to shape the core aims and strategies of this program.

Conversely, if the government was true to its stated community development principles, then the following would arguably have happened in relation to the processes and evaluation of place-based income management. Firstly, any consideration regarding the introduction of income management would have involved extensive consultations with representatives of the local community to discuss how and in what way IM measures might benefit the community. This process would have specifically targeted members of three groups: income security recipients that fell into the two key categories of CPIM and VWPR; the key non-government and government agencies ranging from child protection to family support to housing that currently work with these disadvantaged groups; and representatives of Indigenous community groups given that Indigenous Australians are known to be disproportionately represented in income management measures (Bray et al, 2012). 
Secondly, if there was agreement that IM measures might benefit some community members, there would have been extensive consultation as to how these measures might complement existing services and supports that were known to be effectively assisting these groups of people. And finally, extensive consultations with the three groups above would have been incorporated as key components of the planned evaluation framework in order to measure whether or not IM measures lead to better outcomes for disadvantaged groups and the local community as a whole. However, as we shall see this is not what happened.

\section{Why Greater Shepparton?}

According to the Australian government, the five PBIM locations were chosen on the basis of statistical indicators of disadvantage such as high levels of unemployment, youth unemployment, the numbers of people on income security payments and the length of time of being on payments (FaHCSIA, 2012). However, it is noticeable that none of the five trial sites chosen for PBIM feature in Tony Vinson's list of Australia's most disadvantaged or next most disadvantaged postcodes, except for Playford, SA. Vinson's list is widely regarded as an accepted typology/measure of disadvantaged areas (Vinson, 2007: 26-47).

The particular focus of this study is on the rural Victorian location of Greater Shepparton which does appear to be a relatively disadvantaged area. The Community Services Minister, Jenny Macklin, has stated that Shepparton was chosen because of a relatively high rate of disadvantage including significant numbers of teenage parents, and jobless families with young children (Macklin cited in Doherty and Johnston, 2011).

Shepparton has a population of over 63,000 people. Other key population characteristics include the following: $8.7 \%$ of the workforce are unemployed compared to the national average of $5.6 \%, 18.3 \%$ of the working age population are reliant on income support compared to 12.4 per cent nationally, 66.5 per cent of those receiving unemployment benefits have done so for more than a year compared to 60.1 per cent nationally, one in five of those aged 15-19 years are not engaged in work or further education or training, 3.2 per cent or 2080 people are Indigenous which is higher than the one per cent of Indigenous residents state-wide, 11.7 per cent or 8000 people were born overseas, 10.4 per cent speak a language other than English at home, and 1.9 or 1750 people have poor proficiency in English. Over the past five years, more than 500 humanitarian migrants have settled in the Greater Shepparton area. The three groups in Greater Shepparton that appear to be most 
at risk of unemployment are Indigenous people, humanitarian migrants, and people without post-school qualifications. There is some evidence of major social problems including family violence, crime, substance use, and teenage pregnancy, but arguably no worse than many other areas not targeted for income management trials (Deloitte Access Economics, 2013: 32; Department of Education, Employment and Workplace Relations, 2012: 2; Department of Planning and Community Development, 2011: 32; Greater Shepparton City Council, 2011; Munro, 2012).

\section{The PBIM implementation process in Greater Shepparton}

The PBIM implementation process appears to have followed a strictly topdown model. The Federal Government does not appear to have consulted with any community groups in these locations to clarify whether the introduction of IM programs was warranted, or how they might complement existing support programs (ACOSS, 2012; Lewis, 2012; Tennant, 2012).

The government announced in the Federal Budget of May 2011 that Shepparton would host an income management trial from July 2012. The announcement stated that PBIM would involve a similar approach to the child protection (CPIM) model already trialled in Western Australia (W.A.) which had involved the withholding of up to 70 per cent of parents' income support and family payments to ensure that the needs of their children were met (Macklin, 2011). This was arguably significant given that the W.A. trial had no community development content whatsoever, and merely involved the application of particular IM measures to two specific locations (ORIMA Research, 2010).

The timing of the announcement was arguably problematic in that it focused media attention on the implied weaknesses rather than strengths of the selected communities. Additionally, it was only a number of weeks later that a rationale was released by the government for targeting Shepparton. The first meeting between the Commonwealth departments involved and local community agencies was not held till the end of August 2011 (Tennant, 2012).

The only implied suggestion of the application of a community development framework in Shepparton was a promise to 'give communities a say' in identifying programs relevant to income management recipients in their community (Macklin, 2011: 4). This seemed, however, to be mere rhetoric given the entire trial had been announced in a top-down fashion. An online survey of local welfare agencies in Shepparton found that the great majority of participants (26/33) believed there had been an inadequate level of government consultation with the community (GVCLCP, 2012). Similarly, a meeting 
of a local community forum reported that none of the existing welfare agencies had been directly consulted with by the federal government prior to or following the announcement of Shepparton as a trial site in the May 2011 budget. Particular concern was expressed that the government had 'undervalued and overlooked local expertise and local knowledge of the community' (Shepparton Community Forum on Income Management, 2012, p.2).

To be sure, the government announced the establishment of Local Advisory Groups (LAGs) in the five trial sites in March 2012 to assist in the introduction of income management. Specifically, the LAGs were expected to advise the government on the allocation of money from a Local Solutions Fund aimed at providing additional financial support services and parental support services in Shepparton. These were intended to assist recipients of income management to improve their budgeting skills, work readiness, and their care of children (Greater Shepparton Local Advisory Group, 2013).

In principle, the LAGs could have provided an opportunity for at least a partial bottom-up framework. The stated aims included: engaging local experts, seeking the advice of local communities to identify local employment training priorities, and generally working with the local community to promote participation in the community (GSLAG, 2013; Macklin, 2011). But there is no evidence that the LAGs have served as a serious forum for local input into policy development and decision making around income management. And the funded support services, whilst potentially helpful to the targeted groups, were not introduced as a result of a genuine consultation processes with the local community. The CEO of a major local welfare agency, Goulbourn Valley Family Care, concluded disappointingly that 'At the time of writing it is 14 months since the trial was announced and local engagement is only just beginning. Unless it becomes a central focus soon, Shepparton will not be part of a place-based trial, it will just be a place required to host a trial for the Commonwealth' (Tennant, 2012:7).

\section{The evaluation process in Shepparton}

The official evaluations have played a significant role in the policy debate around income management. In particular, the government has consistently asserted that the evaluation reports demonstrate the effectiveness of income management even though the evidence seems to be highly contested and a number of significant methodological flaws have been identified in these evaluations (Authors, 2013). This lead one academic commentator to argue that 'evaluation itself is not a tool for objectively measuring success or failure, but rather forms a part of the policy process' (Altman and Russell, 2012: 14). 
The government appointed the private sector consultants Deloitte Access Economics to conduct the evaluation of PBIM in the five trial sites including Shepparton. Deloitte stated that they would be undertaking interviews and focus groups with key stakeholders in each PBIM site. However, the proposed consultations, which are not as yet concluded, targeted almost exclusively employees from federal or state government departments (covering child protection, housing and income security) in these regions. The only reference to community or non-government organisations was to discussions with representatives of the Communities for Children program which is actually a federal government program aimed at enhancing parenting skills (Deloitte Access Economics, 2013).

Absent from the proposed consultations are the large number of non-government organisations (covering key areas such as mental health, housing, family violence, emergency relief, drug and alcohol, family support and Indigenous community and culture) which already work with, and often have, extensive knowledge of the lives of income management recipients. Nor is there any stated intention to interview representatives of elected local governments who might be able to comment on the local communal factors that impact on chronic disadvantage. Nor is the evaluation intended to examine what consultation processes good or bad were originally used for the implementation of PBIM in the five trial sites.

\section{Conclusion}

The introduction of PBIM arguably had the potential to introduce a significant community development framework into the application of income management programs. This would have enabled a range of local community stakeholders including service users, community welfare organisations, and representatives of Indigenous organisations to consider how and why IM measures might complement existing community services in order to benefit income security recipients and the local community more generally. The positives of utilizing such a bottom-up approach to policy development and delivery were specifically endorsed by a number of government reports.

But our overview of both the implementation and evaluation processes in the trial site of Shepparton suggests that this potential was mostly ignored. Both processes involved centralized policies being imposed top-down by distant politicians and bureaucrats on a particular location. There is little evidence that the introduction of PBIM in Shepparton utilized local knowledge and expertise regarding the causes of, and potential solutions to, social disadvantage. Little if any contact was made with existing local networks of service 
providers. No attention was given to research evidence confirming the efficacy of place-based programs based on community development principles. Instead, PBIM in Shepparton merely involved the introduction of stigmatizing programs focused narrowly on the individual behaviour of income security recipients in a particular location.

\section{References}

Altman, J., Russell, S. (2012). Too much Dreaming: Evaluations of the Northern Territory National Emergency Response Intervention 2007-2012. Evidence Base, 3, 1-24.

AL-YAMAN, F. and HigGINS, D. (2011). What works to overcome Indigenous disadvantage: key learnings and gaps in the evidence. Canberra: Australian Government.

Australian Council of Social Service (2008). Submission to the Department of Families, Housing, Community Services and Indigenous Affairs: NT Emergency Response Review. Sydney: ACOSS.

Australian Council of Social Service (2010). Submission to Senate Community Affairs Legislation Committee: Inquiry into Social Security and other legislation amendment (Welfare Reform and Reinstatement of Racial Discrimination Act) Bill 2009 and related bills. Sydney: ACOSS.

Australian Council of Social Service (2012). Submission to Senate Community Affairs Committee: Social Security Legislation Amendment Bill 2011. Sydney: ACOSS.

Australian Government (2008). Northern Territory emergency responses: Report of the NTER Review Board. Canberra: Commonwealth of Australia.

Australian Government (2009). Future Directions for the Northern Territory Emergency Response. Canberra: Commonwealth of Australia.

Australian Government (2012a). Helping vulnerable families: targeted income management. Canberra: Australian Government.

Australian Government (2012b). Place Based Income Management in Greater Shepparton. Canberra: Australian Government.

Australian Government (2013). Changes to the Vulnerable Welfare Payment Recipient measure of income management. Canberra: Australian Government.

Australian Social Inclusion Board (2010). Annual Report 2010. Canberra: Commonwealth of Australia.

Australian Social Inclusion Board (2011). Governance models for location based initiatives. Canberra: Commonwealth of Australia.

Authors (2013). The Place-based Income Management Trial in Shepparton: A best practice model for evaluation. Melbourne: Social Inclusion and Social Policy Research Unit, Monash University. 
BEHRENDT L. and MCCAUSLAND R. (2008). Welfare payments and school attendance: An analysis of experimental policy in Indigenous education. Sydney: University of Technology.

Billings, P. (2010). Social welfare experiments in Australia: more trials for Aboriginal communities. Journal of Social Security Law, 17(3), 164-195.

Bray J.R., Gray M., Hand, K., Bradbury, B., EAstman, C. and Katz, I. (2012). Evaluating New Income Management in the Northern Territory: First Evaluation Report. Sydney: Social Policy Research Centre \& Australian National University.

Bryman, A. (2012). Social research methods. (4th ed.). South Melbourne: Oxford University Press.

Buduls, A. (2013). Report of the Independent Review of Centrepay. Canberra: Department of Human Services.

BuCKMASTER, L. and Ey, C. (2012). Is income management working. Canberra: Parliamentary Library.

Buckmaster, L., Ey, C. and Clapdor, M. (2012) Income Management: An overview. Canberra: Parliamentary Library.

BYron, I. (2010). Place-based approaches to addressing disadvantage. Family Matters, 84, 20-27.

Cox, E. (2010). It started with the Intervention. New Matilda, 1 November.

Deloitte Access Economics (2013). Evaluation Framework - Place Based Income Management. Melbourne: Deloitte Access Economics.

Department of Education, Employment and Workplace Relations (DEEWR) (2012). Greater Shepparton Local Government Area: Survey of Employers' Recruitment Experiences. Canberra: Australian Government.

Department of Families, Housing, Community Services and Indigenous Affairs (FaHCSIA) (2012). Families and Children: Place-based income management. Canberra: Australian Government.

Department of Planning and Community Development (2011). Change and disadvantage in the Hume Region, Victoria. Melbourne: State Government Victoria.

DOHERTY, E., JOHNSTON, M. (2011). Cuts in welfare to pay the rent. Herald Sun, 29 October.

Equality Rights Alliance (2011). Women's Experience of Income Management in the Northern Territory. Canberra: Equality Rights Alliance.

Fawcett, B., Goodwin, S., Meagher, G. and Phillips, R. (2010). Social Policy for Social Change. Melbourne: Palgrave Macmillan.

Goulbourn Valley Community Legal Centre Pilot (2012). Shepparton Income Management Survey Report. Bendigo: GVCLCP.

Greater Shepparton City Council (2011), Overseas Arrivals, (http://profile.id.com. au/shepparton/overseas-arrivals? WebID=10, accessed on 22/02/2013). 
Greater Shepparton Local Advisory Group (2013). Better Futures, Local Solutions. http://www.sheppartonlag.com.au, accessed on 31/7/13.

GREEN, V., and ZAPPALA, G. (2000). From welfare to place management: Challenges and developments for service delivery in the community sector. Research and Advocacy Briefing Paper. Sydney: The Smith Family.

Kenny, S. (2011). Developing Communities for the Future. Melbourne: Cengage.

LEWIS, J. (2012). Income control trial concern. Shepparton News, 1 February.

MACKLIN, J. (2010). Income management is improving lives in Western Australia. Media Release, 8 October.

MACKLIN, J. (2011). New approaches to address disadvantage in targeted communities. Media Release, 10 May.

Mendes, P. (2008). Australia's Welfare Wars Revisited. Sydney: UNSW Press.

MORRISON, Z. (2008, June). Place, social inclusion and cultural justice. Presentation given at the Brotherhood of St Laurence and the Department of Planning and Community Development Social Inclusion and Place Based Disadvantage Workshop. Melbourne: BSL.

Munro, P. (2012). Rolling with the punches. Sunday Age, 16 September.

Nicholson, A., Behrendt, L., Vivian, A., Watson, N., and Harris, M. (2009). Will they be heard? A response to the NTER Consultations. Sydney: Jumbunna Indigenous House of Learning.

Orima Research (2010). Evaluation of the child protection scheme of Income Management and Voluntary Income Management Measures in Western Australia. Canberra: Department of Families, Housing, Community Services and Indigenous Affairs.

PEARson, N. (2011). Ineffectual bipartisanship ruins social policy. The Australian, 26 March.

RANDOLPH, B. (2004). Social Inclusion and Place-Focused Initiatives in Western Sydney: A review of current practice. Australian Journal of Social Issues, 39(1), 63-78.

Shepparton Community Forum on Income Management (2012). Minutes of Forum, 24 January.

SMYTH, P. (2008, June). Place based policy at the crossroads. Presentation given at the Brotherhood of St Laurence and the Department of Planning and Community Development Social Inclusion and Place Based Disadvantage Workshop, Melbourne: BSL.

TEnnAnt, D (2012). How 'place' fares in place-based solutions. Victorian Council of Social Service Insight, 7, 34-35.

VINSON T. (2007). Dropping off the edge: the distribution of disadvantage in Australia. Melbourne: Jesuit Social Services.

VINSON, T. (2010). Moving from the Edge: Stories of achieving greater social inclusion. Melbourne: Jesuit Social Services. 
Western Australian Council of Social Service (2011). WACOSS analysis of the ORIMA Research Evaluation of the Child Protection Scheme of Income Management and Voluntary Income Management Measures in Western Australia. Perth: WACOSS.

Wild, R. and ANDERSON, P. (2007). Little Children are Sacred. Darwin, Northern Territory Board Of Inquiry Into The Protection Of Aboriginal Children From Sexual Abuse. 